\title{
Risk factors for mortality in patients with Pseudomonas aeruginosa bacteremia; retrospective study of impact of combination antimicrobial therapy
}

Youn Jeong Kim¹, Yoon Hee Jun', Yang Ree Kim¹, Kang Gyun Park², Yeon Joon Park², Ji Young Kang ${ }^{3^{*}}$ and Sang $\| \mathrm{Kim}^{1}$

\begin{abstract}
Background: Whether the combination of antimicrobial therapy is a factor in mortality in Pseudomonas aeruginosa bacteremia remains to be elucidated. This study investigated the risk factors for mortality in $P$. aeruginosa bacteremia patients and the influence of adequate antimicrobial therapy and combination therapy on clinical outcomes.

Methods: This retrospective study analyzed data of 234 patients with P. aeruginosa bacteremia at a 1,200-bed tertiary teaching university hospital in South Korea between January 2010 and December 2012. Factors associated with mortality were determined. Mortality was compared in patients with adequate empirical and targeted combination therapy, and monotherapy, and inappropriate therapy.

Results: A total of 141 (60.3\%) patients were given appropriate empirical antibiotic treatment (combination therapy in 38 and monotherapy in 103). Among 183 patients (78.2\%) who finally received appropriate targeted treatment, 42 had combination therapy and 141 had monotherapy. The percentage of patients receiving empirical combination therapy was slightly, but not significantly higher, in the survivor group than in the nonsurvivor group (17.0\% [31/182] vs. 13.5\% [7/52], $p=0.74)$. A similar tendency was demonstrated for targeted combination therapy (19.8\% [36/182] vs. $11.5 \%[6 / 52]$, respectively; $p=0.31)$. However, in a subgroup analysis of data from patients $(n=54)$ with an absolute neutrophil count less than $500 / \mathrm{mm}^{3}$, the patients who had appropriate empirical or targeted combination therapy showed better outcomes than those who underwent monotherapy or inappropriate therapy $(p<0.05)$. Mechanical ventilation (odds ratio [OR], 6.93; 95\% confidence interval [Cl], 2.64-18.11; $\mathrm{p}=0.0001$ ), the use of a central venous catheter (OR, 2.95; 95\% Cl, 1.35-6.43; $\mathrm{p}=0.007)$, a high Acute Physiology and Chronic Health Evaluation II score $(\mathrm{OR}, 4.65 ; 95 \% \mathrm{Cl}, 1.95-11.04 ; \mathrm{p}=0.0001)$, and presence of septic shock $(\mathrm{OR}, 2.91 ; 95 \% \mathrm{Cl}, 1.33-6.38 ; \mathrm{p}=0.007)$ were independent risk factors for 14-day mortality.

Conclusions: Disease severity was a critical factor for mortality in our patients with P. aeruginosa bacteremia. Overall, combination therapy had no significant effect on 14-day mortality compared with monotherapy. However, appropriate combination therapy showed a favorable effect on survival in patients with febrile neutropenia.
\end{abstract}

Keywords: Pseudomonas aeruginosa, Bacteremia, Risk factors, Anti-bacterial agents, Combination, Mortality

\footnotetext{
* Correspondence: rkdwldud@catholic.ac.kr

${ }^{3}$ Division of Pulmonology, Department of Internal Medicine, Seoul St. Mary's

hospital, College of Medicine, The Catholic University of Korea, 222

Banpo-daero, Seocho-gu, Seoul 137-701, Republic of Korea

Full list of author information is available at the end of the article
} 


\section{Background}

Pseudomonas aeruginosa represents a common cause of nosocomial infection. Immunocompromised patients such as those with malignancy or neutropenia are at high risk of bacteremia, and P.aeruginosa is one of the commonly isolated pathogens associated with bacteremia in such patients [1,2]. Despite advances in antimicrobial therapy, P.aeruginosa infection remains associated with high mortality ranging of $18 \%-61 \%$ [3].

The therapeutic options for $P$. aeruginosa infection are limited owing to the intrinsic resistance of the bacterium to commonly used antibiotics and the increase in multidrug resistance. The use of more than one kind of antibiotic has been known to be effective for certain patients; the use of a combination of at least two drugs was demonstrated to have a synergistic or additive effect in lowering the risk of receiving an inappropriate empirical therapy, and to prevent the emergence of resistant organisms [4]. Some studies reported that a combination therapy in patients with gram-negative bacteremia resulted in better outcomes than monotherapy $[5,6]$. However, the effects of combination therapies for $P$. aeruginosa infection remain unclear.

The risk factors for mortality in patients with bacteremia are reported to be severe sepsis, neutropenia, and multidrug resistance [7-10]. Whether the adequacy of antimicrobial therapy is a factor for mortality in $P$. aeruginosa bacteremia remains to be elucidated [7,11-13]. In this study, we identified the risk factors for mortality and investigated the effect of the adequacy of antimicrobial therapy in patients with $P$. aeruginosa bacteremia. We also analyzed and compared the effects of combination therapy and monotherapy on 14-day mortality.

\section{Methods}

\section{Study design}

A retrospective study was performed on data from patients (>18 years old) with confirmed clinical signs of $P$. aeruginosa infection between January 2010 and December 2012 at a 1200-bed tertiary teaching hospital in South Korea. $P$. aeruginosa was isolated from at least one set of blood cultures of samples collected from the patients. Only the first bacteremia episode in each patient was included in this study. We assessed the severity of underlying disease using the Acute Physiology and Chronic Health Evaluation (APACHE) II scoring system and the Charlson comorbidity index. We used 14-day overall mortality as the main outcome for the assessment of mortality in patients.

Empirical antimicrobial therapy was defined according to the initial antimicrobial therapy regimens that were administered within 24 hours after blood culture samples were obtained, and before results of susceptibility tests were known. Targeted antimicrobial therapy was defined as specific antibiotics given within 24 hours after the results of antimicrobial susceptibility. Antimicrobial therapy was considered appropriate when the strain showed in vitro susceptibility to the antibiotics administered, and the dosages of the drugs were adequate according to current guidelines [14]. An appropriate combination therapy was defined if two or more antibiotics showed in vitro susceptibility. Appropriate monotherapy was defined as treatment with only one active antibiotic. Aminoglycoside monotherapy was also defined as inadequate therapy. Neutropenia was defined as an absolute neutrophil count $(\mathrm{ANC})<500 / \mathrm{mm}^{3}$ at the time of bacteremia. Multidrug resistance was defined when the strain was resistant to three or more antipseudomonal anti-microbial categories (ciprofloxacin, ceftazidime, piperacillin/tazobactam, meropenem, and amikacin) $[15,16]$. Infection was assessed according to the criteria established by the Centers for Disease Control and Prevention, and patients were considered to have contracted the infection when $P$. aeruginosa was isolated from a sterile site in patients with definite clinical signs of infection [17]. Septic shock was defined in the published guidelines [18].

\section{Microbiological examination}

Identification of $P$. aeruginosa in blood samples was performed using a VITEK 2 automated system (bioMérieux, Marcy l'Etoile, France). Susceptibility results were interpreted according to the guidelines established by the Clinical and Laboratory Standards Institute [19]. Carbapenem resistance was defined as nonsusceptibility to meropenem and/or imipenem in vitro, and isolates with intermediate resistance were regarded as resistant.

\section{Statistically analysis}

The Student $t$-test or the Mann-Whitney $U$ test were used for analysis of continuous variables, and the $\chi^{2}$ test or Fisher's exact test were used for categorical variables. Multivariate analysis using multiple logistic regression was performed for statistically significant factors in the univariate analysis to determine the risk factors associated with 14-day overall mortality. Statistical analysis was performed using SPSS 13.0 (SPSS Inc., Chicago, IL, USA), and $\mathrm{p}<0.05$ was considered statistically significant.

\section{Ethical statement}

This study was approved by the institutional review board of Seoul St. Mary's Hospital, Seoul (KC14RISI0033).

\section{Results}

\section{Demographic characteristics}

During the study period, a total of 234 patients (92 male, 142 female) with P.aeruginosa bacteremia were included. The most common underlying disease was malignancy $(\mathrm{n}=68,29.1 \%)$, followed by hypertension $(\mathrm{n}=52,22.2 \%)$ 
and diabetes mellitus $(\mathrm{n}=47,20.1 \%)$. P. aeruginosa resistance to carbapenem was found in $50.4 \%(n=118)$ of patients. The presumed sources of bacteremia were the respiratory tract $(n=70,29.9 \%)$, abdominal cavity $(n=42$, $17.9 \%)$, urinary tract $(\mathrm{n}=18,7.7 \%)$, postoperative wound $(\mathrm{n}=11,4.7 \%)$, vascular catheter $(\mathrm{n}=4,1.7 \%)$, and other unknown sources $(\mathrm{n}=89,38 \%)$. The overall 14-day mortality was $22.2 \%(\mathrm{n}=52)$, and almost half $(\mathrm{n}=25)$ died within 24 hours after the onset of bacteremia.

Table 1 shows the comparison of the demographic characteristics of the survivors and nonsurvivors. Neutropenia was more frequent among the patients who died than among those who survived (34.6\% [18/52] vs. $19.8 \%$ [36/182], $\mathrm{p}=0.02)$. Nonsurvivors showed a higher APACHE II score (18 vs. $11, \mathrm{p}=0.0001)$ and had a higher rate of septic shock $(53.8 \%$ [28/52] vs. $18.7 \%$ [34/182], $\mathrm{p}=0.0001)$ than the survivors. The use of a central venous catheter $(69.2 \%$ [36/52] vs. 33.5\% [61/182], $\mathrm{p}=0.0001)$, foley catheter $(53.8 \%$ [28/52] vs. $12.1 \%$ [22/182], $\mathrm{p}=$ $0.0001)$ and mechanical ventilator $(38.5 \%$ [20/52] vs. $6.6 \%[12 / 182], \mathrm{p}=0.0001$ ) was significantly more frequent among the nonsurvivors than among the survivors.

In the univariate analysis, 14-day mortality was associated with neutropenia (odds ratio [OR], 2.14; 95\%

Table 1 Comparison of demographic characteristics of survivors and non survivors of Pseudomonas aeruginosa bacteremia

\begin{tabular}{|c|c|c|c|c|}
\hline & Total $(n=234)$ & Non survivors $(n=52)$ & Survivors $(n=182)$ & $P$ value \\
\hline Age, median years (range) & $57(19 \sim 93)$ & $60.5(19 \sim 84)$ & $56(21 \sim 93)$ & 0.35 \\
\hline Male sex & $92(39.3 \%)$ & $23(44.2 \%)$ & 69 (37.9\%) & 0.41 \\
\hline \multicolumn{5}{|l|}{ Underlying disease } \\
\hline Diabetes mellitus & 47 (20.1\%) & $8(15.4 \%)$ & $39(21.4 \%)$ & 0.34 \\
\hline Hypertension & $52(22.2 \%)$ & $11(21.2 \%)$ & $41(22.5 \%)$ & 0.83 \\
\hline Liver cirrhosis & $13(5.6 \%)$ & $2(3.8 \%)$ & $11(6.0 \%)$ & 0.54 \\
\hline Transplant & $34(14.5 \%)$ & $10(19.2 \%)$ & $24(13.2 \%)$ & 0.27 \\
\hline Solid organ & $8(3.4 \%)$ & $1(1.9 \%)$ & $7(3.8 \%)$ & \\
\hline Bone marrow & $26(11.1 \%)$ & $9(17.3 \%)$ & $17(9.3 \%)$ & \\
\hline Malignancy & $68(29.1 \%)$ & $14(26.9 \%)$ & $54(29.7 \%)$ & 0.70 \\
\hline Dialysis & $11(4.7 \%)$ & $2(3.8 \%)$ & $9(4.9 \%)$ & 0.74 \\
\hline Neutropenia & $54(23.1 \%)$ & $18(34.6 \%)$ & $36(19.8 \%)$ & 0.02 \\
\hline Hospitalization in the preceding 90 days & $98(41.9 \%)$ & $26(50.0 \%)$ & $72(39.6 \%)$ & 0.18 \\
\hline APACHE II score, median (IQR) & $12(0 \sim 40)$ & $18(5 \sim 40)$ & $11(0 \sim 28)$ & 0.0001 \\
\hline Charlson comobidity index, median (IQR) & $3(0 \sim 13)$ & $4(1 \sim 10)$ & $4(0 \sim 13)$ & 0.57 \\
\hline Septic shock & $62(26.7 \%)$ & $28(53.8 \%)$ & $34(18.7 \%)$ & 0.0001 \\
\hline \multicolumn{5}{|l|}{ Invasive procedure } \\
\hline Central venous catheter & $97(41.5 \%)$ & $36(69.2 \%)$ & $61(33.5 \%)$ & 0.0001 \\
\hline Surgical drainage & $39(16.7 \%)$ & $8(15.4 \%)$ & $31(17.0 \%)$ & 0.78 \\
\hline Foley catheter & $50(21.4 \%)$ & $28(53.8 \%)$ & $22(12.1 \%)$ & 0.0001 \\
\hline Mechanical ventilator & $32(13.7 \%)$ & $20(38.5 \%)$ & $12(6.6 \%)$ & 0.0001 \\
\hline The length of stay before bacteremia, median days (IQR) & $1(0 \sim 92)$ & $1(0 \sim 28)$ & $2.5(0 \sim 92)$ & 0.2 \\
\hline Source of bacteremia & & & & 0.006 \\
\hline Pneumonia & $70(29.9 \%)$ & $27(51.9 \%)$ & $43(23.6 \%)$ & \\
\hline Urinary tract & $18(7.7 \%)$ & $2(3.8 \%)$ & $16(8.8 \%)$ & \\
\hline Vascular catheter-related & $4(1.7 \%)$ & $1(1.9 \%)$ & $3(1.6 \%)$ & \\
\hline Intra-abdomen & $42(17.9 \%)$ & $7(13.5 \%)$ & $35(19.2 \%)$ & \\
\hline Postoperative wound & $11(4.7 \%)$ & $1(1.9 \%)$ & $10(5.5 \%)$ & \\
\hline Unknown & 89 (38.0\%) & $14(26.9 \%)$ & $75(41.2 \%)$ & \\
\hline Length of hospital stay, median days (IQR) & $17(1 \sim 364)$ & $12(1 \sim 364)$ & $18(1 \sim 92)$ & 0.08 \\
\hline Carbapenem resistance & $118(50.4 \%)$ & $26(50.0 \%)$ & $92(50.5 \%)$ & 0.94 \\
\hline Multidrug resistance & $6(2.6 \%)$ & $3(5.8 \%)$ & $3(1.6 \%)$ & 0.09 \\
\hline
\end{tabular}


confidence interval $[\mathrm{CI}], 1.09-4.22 ; \mathrm{p}=0.03)$, the use of a mechanical ventilator (OR, 8.85; 95\% CI, 3.94-19.88; $\mathrm{p}=0.0001)$, the use of a central venous catheter $(\mathrm{OR}, 4.46$; 95\% CI, 2.29-8.67; $\mathrm{p}=0.0001$ ), a high APACHE II score (OR, 8.88; 95\% CI, 4.06-19.38; $\mathrm{p}=0.0001$ ), and the presence of septic shock (OR, 5.08; 95\% CI, 2.63-9.83; $\mathrm{p}=0.0001$ ) (Table 2). The multivariate analysis revealed that the use of a mechanical ventilator (OR, 6.93; 95\% CI, 2.64-18.11; $\mathrm{p}=0.0001)$, the use of a central venous catheter (OR, 2.95; 95\% CI, 1.35-6.43; $\mathrm{p}=0.007$ ), a high APACHE II score (OR, 4.65; 95\% CI, 1.95-11.04; $\mathrm{p}=0.0001$ ), and the presence of septic shock (OR, 2.91; 95\% CI, 1.336.38; $\mathrm{p}=0.007$ ) were the independent risk factors for 14-day mortality (Table 2).

A total of 141 (60.3\%) patients were given appropriate empirical antibiotic treatment, which included combination therapy in 38 patients $(16.2 \%)$ and monotherapy in 103 patients (44.0\%). Among 183 patients (78.2\%) who were finally treated with appropriate appropriate targeted treatment, $42(17.9 \%)$ were given combination therapy and 141 (60.3\%) were given monotherapy. Table 3 describes the administered adequate antibiotics in detail. Adequate empirical antimicrobials used in monotherapy were as follows: $88 \beta$-lactam, 8 fluoroquinolone, and 7 colistin, whereas targeted monotherapy consisted of 114 $\beta$-lactam, 20 fluoroquinolone, and 7 colistin. $\beta$-lactam and aminoglycoside was the most frequent combination in patients treated with adequate empirical combination
Table 3 Description of administered antibiotics in patients receiving adequate treatment

\begin{tabular}{|c|c|c|}
\hline \multicolumn{3}{|l|}{ Adequate monotherapy } \\
\hline & Empirical $(n=103)$ & Targeted $(n=141)$ \\
\hline B-lactam & $88(85.4 \%)$ & $114(80.9 \%)$ \\
\hline $\begin{array}{l}\text { Antipseudomonal } \\
\text { penicillin }\end{array}$ & $24(23.3 \%)$ & $31(21.9 \%)$ \\
\hline Cephalosporin & $45(43.7 \%)$ & $36(25.5 \%)$ \\
\hline Carbapenem & $19(18.4 \%)$ & $47(33.3 \%)$ \\
\hline Fluoroquinolones & $8(7.8 \%)$ & $20(14.2 \%)$ \\
\hline Colistin & $7(6.8 \%)$ & $7(4.9 \%)$ \\
\hline \multicolumn{3}{|l|}{ Adequate combination therapy } \\
\hline & Empirical $(n=38)$ & Targeted $(n=42)$ \\
\hline B-lactam + aminoglycosides & $32(84.2 \%)$ & $33(78.6 \%)$ \\
\hline $\begin{array}{l}\text { Antipseudomonal } \\
\text { penicillin }\end{array}$ & $6(68.4 \%)$ & $25(59.6 \%)$ \\
\hline Cephalosporin & $26(15.8 \%)$ & $3(7.1 \%)$ \\
\hline Carbapenem & 0 & $5(11.9 \%)$ \\
\hline B-lactam + fluoroquinolones & $5(13.2 \%)$ & $7(16.7 \%)$ \\
\hline $\begin{array}{l}\text { Antipseudomonal } \\
\text { penicillin }\end{array}$ & $3(7.9 \%)$ & $2(4.8 \%)$ \\
\hline Cephalosporin & $2(5.3 \%)$ & $4(9.5 \%)$ \\
\hline Carbapenem & 0 & $1(2.4 \%)$ \\
\hline Colistin + fluoroquinolones & $1(2.6 \%)$ & $1(2.4 \%)$ \\
\hline Colistin + aminoglycoside & 0 & $1(2.4 \%)$ \\
\hline
\end{tabular}

Table 2 Risk factors associated with 14-day mortality in patients with $P$. aeruginosa bacteremia

\begin{tabular}{|c|c|c|c|c|c|c|}
\hline \multirow[b]{2}{*}{ Risk factor } & \multicolumn{3}{|c|}{ Univariate analysis } & \multicolumn{3}{|c|}{ Multivariate analysis } \\
\hline & OR & $95 \% \mathrm{Cl}$ & $P$ value & OR & $95 \% \mathrm{Cl}$ & $P$ value \\
\hline Age $>60$ (years) & 1.42 & $0.77-2.64$ & 0.26 & & & \\
\hline Neutropenia & 2.14 & $1.09-4.22$ & 0.03 & 1.45 & $0.63-3.33$ & 0.37 \\
\hline Mechanical ventilator & 8.85 & $3.94-19.88$ & 0.0001 & 6.93 & $2.64-18.11$ & 0.0001 \\
\hline Central venous catheter & 4.46 & $2.29-8.67$ & 0.0001 & 2.95 & $1.35-6.43$ & 0.007 \\
\hline APACHE II score $\geq 13$ & 8.88 & $4.06-19.38$ & 0.0001 & 4.65 & $1.95-11.04$ & 0.0001 \\
\hline Septic shock & 5.08 & $2.63-9.83$ & 0.0001 & 2.91 & $1.33-6.38$ & 0.007 \\
\hline Carbapenem resistance & 1.02 & $0.55-1.89$ & 0.94 & & & \\
\hline Multidrug resistance & 3.65 & $0.72-18.67$ & 0.12 & & & \\
\hline Pneumonia as a source of bacteremia & 1.01 & $0.51-2.01$ & 0.96 & & & \\
\hline \multicolumn{7}{|l|}{ Empirical therapy } \\
\hline Appropriate combination therapy & 0.82 & $0.31-2.14$ & 0.69 & & & \\
\hline Appropriate monotherapy & 1.17 & $0.59-2.28$ & 0.64 & & & \\
\hline Inappropriate therapy & 1.0 (ref) & & & & & \\
\hline \multicolumn{7}{|l|}{ Targeted therapy } \\
\hline Appropriate combination therapy & 0.44 & $0.37-1.61$ & 0.49 & & & \\
\hline Appropriate monotherapy & 0.78 & $0.15-1.27$ & 0.13 & & & \\
\hline Inappropriate therapy & 1.0 (ref) & & & & & \\
\hline
\end{tabular}

$O R=$ odd rations; $C l=$ confidential interval; $C R=$ carbapenem-resistance. 
therapy $(84.2 \%[32 / 38])$, and in adequate targeted combination therapy $(78.6 \%$ [33/42]). The appropriateness of empirical therapy was not significantly different between the survivor and nonsurvivor groups $(61.5 \%$ [32/52] vs. $60.4 \%$ [110/182], $\mathrm{p}=0.89$ ), and the appropriateness of targeted therapy was also not different between the two groups (73.1\% [38/52] vs. 79.7\% [145/182], $\mathrm{p}=0.31$ ).

Patients with P.aeruginosa bacteremia who received combination empirical therapy or targeted therapy did not show better outcomes than those who receivied monotherapy or inadequate therapy (Table 4). The percentage of patients receiving empirical combination therapy was slightly, but not significantly higher, in the survivor group than in the nonsurvivor group $(17.0 \%$ [31/182] vs. $13.5 \%$ [7/52], $\mathrm{p}=0.74)$. A similar tendency was found in the group receiving targeted therapy (19.8\% [36/182] vs. $11.5 \%$ [6/52], respectively; $\mathrm{p}=0.31$ ). However, a subgroup analysis of data from patients $(n=54)$ with an $\mathrm{ANC}<500 / \mathrm{mm}^{3}$ indicated that that those who underwent appropriate empirical combination therapy showed better outcomes than those who underwent appropriate empirical monotherapy or inappropriate therapy $(\mathrm{p}=0.001)$. In addition, patients who underwent appropriate targeted combination therapy also showed a more favorable outcome than those who underwent appropriate targeted monotherapy or inappropriate therapy $(\mathrm{p}=0.01)($ Table 4$)$.

\section{Discussion}

The effect of appropriate therapies and combination therapies on mortality in patients with $P$. aeruginosa bacteremia remains to be clarified. In this study, the overall in-hospital 14-day mortality rate in the patients with $P$. aeruginosa bacteremia was as high as $22.2 \%$. The independent predictors for mortality among patients with $P$. aeruginosa bacteremia were the use of a mechanical ventilator, the use of a central venous catheter, a high APACHE II score, and a clinical presentation of septic shock. We did not demonstrate a beneficial effect of adequate empirical or targeted combination therapy on survival, although there was a tendency towards a protective effect on mortality. However, in the subgroup with neutropenia, adequate empirical or targeted combination therapy was associated with a significantly lower 14-day mortality rate. The condition of patients with $P$. aeruginosa bacteremia deteriorated rapidly, and most nonsurvivors died on the day of onset. Therefore, early appropriate treatment plays an important role in the outcome among $P$. aeruginosa bacteremia patients, and some studies have reported that inappropriate antibiotic therapy is associated with poor prognosis $[11,20]$. There are several reports that a clinical presentation of sepsis is a strong predictor of mortality consistent with the present study $[7,13,21]$. As neutropenia may be a factor for increased mortality in patients with hematologic or solid malignancy, we analyzed the relationship between adequacy of antibiotic therapy and mortality after stratifying the cases in our study according to the presence of neutropenia $[10,22]$. Our results demonstrated that adequate combination antimicrobial therapy was associated with a decreased mortality rate in patients with neutropenia. Combination therapy is advantageous in terms of preventing the emergence of resistant organisms, its synergistic effect, and its ability to increase the likelihood of organisms being susceptible to at least one of the component antibiotics [4]. A meta-analysis by Safdar et al. demonstrated that combination therapy could reduce the mortality rate in patients with $P$. aeruginosa infection; however, another study indicated that combination therapy did not affect patient outcomes [21,23]. There is controversy whether combination therapy for $P$. aeruginosa is superior to monotherapy in improving the survival of

Table 4 Comparison of outcomes according to adequacy of antibiotics

\begin{tabular}{|c|c|c|c|c|c|}
\hline & & & Survivor $(n=182)$ & Non survivor $(n=52)$ & $P$ value \\
\hline \multirow[t]{6}{*}{ All patients $(n=234)$} & Empirical & Combination & $31(17.0 \%)$ & $7(13.5 \%)$ & 0.74 \\
\hline & & Monotherapy & $78(42.9 \%)$ & $25(48.1 \%)$ & \\
\hline & & Inappropriate & $31(17.0 \%)$ & $7(13.5 \%)$ & \\
\hline & Targeted & Combination & $36(19.8 \%)$ & $6(11.5 \%)$ & 0.31 \\
\hline & & Monotherapy & 109 (59.9\%) & $32(61.5 \%)$ & \\
\hline & & Inappropriate & 37 (20.3\%) & $14(26.9 \%)$ & \\
\hline \multirow[t]{6}{*}{ Patients with neutropenia $(n=54)$} & Empirical & Combination & 19 (52.7\%) & $4(22.2 \%)$ & 0.001 \\
\hline & & Monotherapy & $16(44.4 \%)$ & $7(38.8 \%)$ & \\
\hline & & Inadequate & $1(2.7 \%)$ & $7(38.8 \%)$ & \\
\hline & Targeted & Combination & $21(58.3 \%)$ & $10(55.5 \%)$ & 0.01 \\
\hline & & Monotherapy & $14(38.8 \%)$ & $3(16.7 \%)$ & \\
\hline & & Inadequate & $1(2.7 \%)$ & $5(27.7 \%)$ & \\
\hline
\end{tabular}


the patients with $P$. aeruginosa bacteremia. Our study showed that combination therapy may have a significant beneficial effect in a subgroup of patients with neutropenia One meta-analysis showed that there was no significant difference between ß-lactam-aminoglycoside combination therapy and monotherapy in patients with febrile neutropenia, however the analysis did not target only patients with $P$. aeruginosa infection, and did not investigate the adequacy of antimicrobial therapy [24]. Our results are consistent with those of a prospective observational study that reported that combination therapy was beneficial only in neutropenic patients, although the study included patients with Gram-negative bacteremia, and not specifically $P$. aeruginosa infection [25]. We suggest that combination empirical therapy should be considered for febrile neutropenic patients, if there is a risk of Pseudomonas infection. In our non-neutropenic patients, combination therapy for $P$. aeruginosa bacteremia did not appear to confer a significant additional beneficial effect, and disease severity such as the presence of septic shock and high APACHE II score played an important role in the treatment outcome.

In our study, approximately $50 \%$ of all patients were infected with carbapenem-resistant $P$. aeruginosa, indicating a high prevalence of antibiotic resistance in our hospital compared with the approximately $30 \%$ prevalence rate reported for the general Korean population [26]. Recently, cases of carbapenem resistance of gramnegative isolates have been increasing, as in our hospital [26]. The high prevalence of cases is likely the result of our hospital population, including a high percentage of malignancy cases and transplant recipients. Carbapenem resistance or multidrug resistance was not an independent factor for higher 14-day mortality in our study. There is some controversy with regard to the effect of antibiotic resistance on mortality. Some studies have reported that the clinical presentation or the use of appropriate antibiotics, rather than resistance, were predictors of mortality in patients with $P$. aeruginosa bacteremia $[27,28]$. Further studies are required to clarify this point.

The major limitation of this study was its retrospective nature in a single center and diversity of underlying disease and condition of bacteremia. Second, the choice of antibiotics depended on the physician's opinion, which could be a source of bias. We did not analyze outcome based on the antibiotic administered. Third, appropriate therapy was defined as the administration of antibiotics to which the isolate had in vitro susceptibility. In our study, colistin monotherapy was defined as adequate if $P$. aeruginosa was susceptible to colistin in vitro. Colistin has been reintroduced for the treatment of multidrug resistant Gram-negative bacilli infections, and there have been reports of the synergy of colistin combined with other antibiotics [29]. However, it remains questionable in clinical practice whether colistin monotherapy is inferior to combination therapy in patients with $P$. aeruginosa infection, especially multidrug-resistant species.

\section{Conclusion}

The mortality rate of $P$. aeruginosa bacteremia remains high, despite advances in antibiotic therapy. High APACHE II score and presence of septic shock was the critical factor for mortality in $P$. aeruginosa bacteremia, and combination therapy did not significantly reduce the overall 14-day mortality rate. However, in cases with febrile neutropenia, combination therapy showed a beneficial effect on survival, and early appropriate combination treatment was associated with a positive effect on patient outcomes.

\section{Competing interests}

The authors declare that they have no competing interests.

\section{Authors' contributions}

YJK participated in the design of the study, performed the statistical analysis, wrote the paper and drafted the manuscript. YHJ participated in its design and performed critical review. YRK and YJP performed critical review. KGP collected the data. JYK and SIK participated in its design and coordination, and performed critical review. All authors read and approved the final manuscript.

\section{Acknowledgements}

The authors wish to acknowledge the financial support of the Catholic Medical Center Research Foundation made in the program year of 2013.

\section{Author details}

${ }^{1}$ Division of infectious disease, Department of Internal Medicine, Seoul St. Mary's hospital, College of Medicine, The Catholic University of Korea, Seoul, Korea. ${ }^{2}$ Department of Laboratory Medicine,Seoul St. Mary's hospital, College of Medicine, The Catholic University of Korea, Seoul, Korea. ${ }^{3}$ Division of Pulmonology, Department of Internal Medicine, Seoul St. Mary's hospital, College of Medicine, The Catholic University of Korea, 222 Banpo-daero, Seocho-gu, Seoul 137-701, Republic of Korea.

Received: 27 August 2013 Accepted: 19 March 2014

Published: 24 March 2014

\section{References}

1. Papagheorghe R: Bloodstream infections in immunocompromised hosts. Roum Arch Microbiol Immunol 2012, 71:87-94.

2. Samonis G, Vardakas KZ, Maraki S, Tansarli GS, Dimopoulou D, Kofteridis DP, Andrianaki AM, Falagas ME: A prospective study of characteristics and outcomes of bacteremia in patients with solid organ or hematologic malignancies. Support Care Cancer 2013, 21:2521-2526.

3. Bassetti M, Righi E, Viscoli C: Pseudomonas aeruginosa serious infections: mono or combination antimicrobial therapy? Curr Med Chem 2008, 15:517-522

4. Van Delden C: Pseudomonas aeruginosa bloodstream infections: how should we treat them? Int J Antimicrob Agents 2007, 30(Suppl 1):S71-S75.

5. Anderson ET, Young LS, Hewitt WL: Antimicrobial synergism in the therapy of gram-negative rod bacteremia. Chemotherapy 1978, 24:45-54.

6. Paul M, Benuri-Silbiger I, Soares-Weiser K, Leibovici L: Beta lactam monotherapy versus beta lactam-aminoglycoside combination therapy for sepsis in immunocompetent patients: systematic review and meta-analysis of randomised trials. BMJ 2004, 328:668.

7. Suarez C, Pena C, Tubau F, Gavalda L, Manzur A, Dominguez MA, Pujol M, Gudiol F, Ariza J: Clinical impact of imipenem-resistant Pseudomonas aeruginosa bloodstream infections. J Infect 2009, 58:285-290.

8. Pena C, Gomez-Zorrilla S, Oriol I, Tubau F, Dominguez MA, Pujol M, Ariza J: Impact of multidrug resistance on Pseudomonas aeruginosa ventilator- 
associated pneumonia outcome: predictors of early and crude mortality. Eur J Clin Microbiol Infect Dis 2013, 32:413-420.

9. Morata L, Cobos-Trigueros N, Martinez JA, Soriano A, Almela M, Marco F, Sterzik H, Nunez R, Hernandez C, Mensa J: Influence of multidrug resistance and appropriate empirical therapy on the 30-day mortality rate of Pseudomonas aeruginosa bacteremia. Antimicrob Agents Chemother 2012, 56:4833-4837.

10. Norgaard M, Larsson H, Pedersen G, Schonheyder HC, Sorensen HT: Risk of bacteraemia and mortality in patients with haematological malignancies. Clin Microbiol Infect 2006, 12:217-223.

11. Kang Cl, Kim SH, Kim HB, Park SW, Choe YJ, Oh MD, Kim EC, Choe KW: Pseudomonas aeruginosa bacteremia: risk factors for mortality and influence of delayed receipt of effective antimicrobial therapy on clinical outcome. Clin Infect Dis 2003, 37:745-751.

12. Tuon FF, Gortz LW, Rocha JL: Risk factors for pan-resistant Pseudomonas aeruginosa bacteremia and the adequacy of antibiotic therapy. Braz $J$ Infect Dis 2012, 16:351-356.

13. Schechner V, Gottesman T, Schwartz O, Korem M, Maor Y, Rahav G, Karplus R, Lazarovitch T, Braun E, Finkelstein R, Lazarovitch T, Braun E, Finkelstein $R$, Lachish T, Wiener-Well Y, Alon D, Chowers M, Bardenstein R, Zimhony O, Paz A, Potasman I, Giladi M, Schwaber MJ, Klarfeld-Lidji S, Hochman M, Marchaim D, Carmeli Y: Pseudomonas aeruginosa bacteremia upon hospital admission: risk factors for mortality and influence of inadequate empirical antimicrobial therapy. Diagn Microbiol Infect Dis 2011, 71:38-45.

14. Clinical and Laboratory Standards Institute: Performance standards for antimicrobial susceptibility testing. In Informational Supplement M100-S22. Wayne, PA, USA: CLSI; 2012.

15. Falagas ME, Karageorgopoulos DE: Pandrug resistance (PDR), extensive drug resistance (XDR), and multidrug resistance (MDR) among Gramnegative bacilli: need for international harmonization in terminology. Clin Infect Dis 2008, 46:1121-1122. author reply 1122.

16. Magiorakos AP, Srinivasan A, Carey RB, Carmeli Y, Falagas ME, Giske CG, Harbarth S, Hindler JF, Kahlmeter G, Olsson-Liljequist B, Paterson DL, Rice LB, Stelling J, Struelens MJ, Vatopoulos A, Weber JT, Monnet DL: Multidrugresistant, extensively drug-resistant and pandrug-resistant bacteria: an international expert proposal for interim standard definitions for acquired resistance. Clin Microbiol Infect 2012, 18:268-281.

17. CDC: CDC/NHSN surveillance definition; 2014. www.cdc.gov/nhsn/PDFs/ pscManual/17pscNosInfDef_current.pdf.

18. Dellinger RP, Levy MM, Rhodes A, Annane D, Gerlach H, Opal SM, Sevransky JE, Sprung CL, Douglas IS, Jaeschke R, Osborn TM, Nunnally ME, Townsend SR, Reinhart K, Kleinpell RM, Angus DC, Deutschman CS, Machado FR, Rubenfeld GD, Webb SA, Beale RJ, Vincent JL, Moreno R, Surviving Sepsis Campaign Guidelines Committee including the Pediatric Subgroup: Surviving sepsis campaign: international guidelines for management of severe sepsis and septic shock: 2012. Crit Care Med 2013, 41:580-637.

19. Clinical and Laboratory Standards Institute: Performance standards for antimicrobial susceptibility testing. In Informational Supplement M100-S16. Wayne, PA, USA: CLSI; 2008.

20. Cheong HS, Kang Cl, Wi YM, Ko KS, Chung DR, Lee NY, Song JH, Peck KR: Inappropriate initial antimicrobial therapy as a risk factor for mortality in patients with community-onset Pseudomonas aeruginosa bacteraemia. Eur J Clin Microbiol Infect Dis 2008, 27:1219-1225.

21. Chamot E, Boffi El Amari E, Rohner P, Van Delden C: Effectiveness of combination antimicrobial therapy for Pseudomonas aeruginosa bacteremia. Antimicrob Agents Chemother 2003, 47:2756-2764.

22. Chindaprasirt J, Wanitpongpun C, Limpawattana P, Thepsuthammarat K, Sripakdee W, Sookprasert A, Wirasorn K: Mortality, length of stay, and cost associated with hospitalized adult cancer patients with febrile neutropenia. Asian Pac J Cancer Prev 2013, 14:1115-1119.

23. Safdar N, Handelsman J, Maki DG: Does combination antimicrobial therapy reduce mortality in Gram-negative bacteraemia? A meta-analysis. Lancet Infect Dis 2004, 4:519-527.

24. Paul M, Soares-Weiser K, Leibovici L: Beta lactam monotherapy versus beta lactam-aminoglycoside combination therapy for fever with neutropenia: systematic review and meta-analysis. BMJ 2003, 326:1111.

25. Leibovici L, Paul M, Poznanski O, Drucker M, Samra Z, Konigsberger H, Pitlik SD: Monotherapy versus beta-lactam-aminoglycoside combination treatment for gram-negative bacteremia: a prospective, observational study. Antimicrob Agents Chemother 1997, 41:1127-1133.

26. Lee K, Kim MN, Kim JS, Hong HL, Kang JO, Shin JH, Park YJ, Yong D, Jeong SH, Chong Y: Further increases in carbapenem-, amikacin-, and fluoroquinolone- resistant isolates of Acinetobacter spp. and P. aeruginosa in Korea: KONSAR study 2009. Yonsei Med J 2011, 52:793-802.

27. Suarez C, Pena C, Gavalda L, Tubau F, Manzur A, Dominguez MA, Pujol M, Gudiol F, Ariza J: Influence of carbapenem resistance on mortality and the dynamics of mortality in Pseudomonas aeruginosa bloodstream infection. Int I Infect Dis 2010, 14(Suppl 3):e73-e78.

28. Blot S, Vandewoude K, De Bacquer D, Colardyn F: Nosocomial bacteremia caused by antibiotic-resistant gram-negative bacteria in critically ill patients: clinical outcome and length of hospitalization. Clin Infect Dis 2002, 34:1600-1606.

29. Karaoglan I, Zer Y, Bosnak VK, Mete AO, Namiduru M: In vitro synergistic activity of colistin with tigecycline or beta-lactam antibiotic/beta-lactamase inhibitor combinations against carbapenem-resistant Acinetobacter baumannii. J Int Med Res 2013, 41:1830-1837.

doi:10.1186/1471-2334-14-161

Cite this article as: Kim et al: Risk factors for mortality in patients with Pseudomonas aeruginosa bacteremia; retrospective study of impact of combination antimicrobial therapy. BMC Infectious Diseases 2014 14:161.

\section{Submit your next manuscript to BioMed Central and take full advantage of:}

- Convenient online submission

- Thorough peer review

- No space constraints or color figure charges

- Immediate publication on acceptance

- Inclusion in PubMed, CAS, Scopus and Google Scholar

- Research which is freely available for redistribution

Submit your manuscript at www.biomedcentral.com/submit
C Biomed Central 